\title{
The use of unirradiated and $\gamma$-irradiated zinc oxide nanoparticles as a preservative in cosmetic preparations
}

\author{
This article was published in the following Dove Press journal: \\ International Journal of Nanomedicine \\ 12 September 2017 \\ Number of times this article has been viewed
}

\author{
Alaa El-Dien MS Hosny' \\ Mona T Kashef' \\ Hadeer A Taher ${ }^{2}$ \\ Zeinab E El-Bazza² \\ 'Department of Microbiology and \\ Immunology, Faculty of Pharmacy, \\ Cairo University, Cairo, Egypt; \\ ${ }^{2}$ Department of Drug Radiation \\ Research, National Center for \\ Radiation Research and Technology, \\ Atomic Energy Authority, Cairo, Egypt
}

Correspondence: Mona T Kashef Department of Microbiology and Immunology, Faculty of Pharmacy, Cairo University, Kasr El-Eini St, Cairo II 562, Egypt

$\mathrm{Tel}+20223639307$

Fax +20223628426

Email mona.kashef@pharma.cu.edu.eg
Purpose: Microbial contamination of different cosmetic preparations, as a result of preservative failure, presents a major public health threat. Also, most of the known preservatives have serious consumer side effects. The antimicrobial activity of zinc oxide nanoparticles ( $\mathrm{ZnO} \mathrm{NP})$ is well documented. Therefore, we aimed to determine the possible use of unirradiated and $\gamma$-irradiated $\mathrm{ZnO} \mathrm{NP}$ as a cosmetic preservative.

Methods: The possible use of $\mathrm{ZnO}$ NP as a preservative was tested and compared to commonly used preservatives using a challenge test. Their activity was tested in six different types of preparations. The effect of $\gamma$ radiation on the antimicrobial activity of $\mathrm{ZnO} \mathrm{NP}$ was tested through determination of the obtained zone diameters against different microorganisms and the total aerobic microbial count in tested preparations. The antimicrobial activity, of unirradiated and $\gamma$-irradiated $\mathrm{ZnO} \mathrm{NP}$ during storage was also determined.

Results: ZnO NP were superior to other commonly used preservatives in all tested cosmetic preparations. They pass the challenge test in all types of tested preparations. $\gamma$ irradiation enhanced their antimicrobial activity in all tested preparations. The irradiation causes a reduction in NP sizes that is directly proportional to the applied radiation dose. Upon storage, ZnO NP were effective in maintaining the microbial count of the product within the acceptable range. Their activity in stored products was enhanced by $\gamma$ irradiation.

Conclusion: Unirradiated and $\gamma$-irradiated $\mathrm{ZnO}$ NP can be used as effective preservatives. They are compatible with the components of all tested products. $\gamma$ irradiation enhanced the antimicrobial activity of $\mathrm{ZnO} \mathrm{NP}$.

Keywords: antimicrobial activity, challenge test, $\gamma$ irradiation, particle size, preservative, zinc oxide nanoparticles

\section{Introduction}

Microbial contamination of cosmetics is very crucial because of their daily use and direct contact with the skin. Their contamination arises from various sources such as environment, raw materials, and manufacturing process. ${ }^{1}$ Several studies have revealed that cosmetic products may be contaminated with pathogenic microorganisms to different levels. ${ }^{1-4}$ Escherichia coli, Pseudomonas species, Staphylococcus species, and Bacillus species were the most commonly recovered bacteria from cosmetics. ${ }^{5,6}$

Contamination with pathogenic organisms can adversely affect the product stability and cause hazards to consumer health. ${ }^{7}$ In addition, commonly used preservatives such as parabens, sodium benzoate, and phenoxyethanol have a well-known skin-sensitizing potential, and repeated exposure is responsible for the occurrence of contact allergy, especially when combined with other allergens and skin irritants. ${ }^{8}$ The cosmetic 
industry is also facing some restrictions regarding the use of some preservatives like parabens, which are accused of causing breast cancer. ${ }^{9}$ Therefore, there is a need for incorporation of more safe and effective antimicrobial agents in cosmetics.

Inorganic powders such as zinc oxide $(\mathrm{ZnO})$ represent a promising alternative to these harmful organic preservatives. $\mathrm{ZnO}$ is listed as "generally recognized as safe" by the US Food and Drug Administration (21CFR 182.8991) and is widely used in topical pharmaceutical preparations. ${ }^{10}$ Several mechanisms have been proposed to account for the antimicrobial activity of $\mathrm{ZnO}$ : photochemical reactions coming from the semi-conductive properties of $\mathrm{ZnO}$ which generate reactive oxygen species capable of damaging the cell membranes of microorganisms, the partial dissolution of $\mathrm{ZnO}$ particles which releases cytotoxic $\mathrm{Zn}^{2+}$ ions in water, and the adsorption of $\mathrm{ZnO}$ particles onto the microbial cells that destabilizes the microbial cell walls. ${ }^{9}$ The compatibility of $\mathrm{ZnO}$ with different formulation ingredients in some topical preparations had been described by Pasquet et al. ${ }^{10}$

Nanotechnology represents a new research area of modern science. The antimicrobial activity of metal oxide nanomaterials has become of great concern. Their inhibitory effect on both Gram-positive and Gram-negative bacteria has been recently reported and zinc oxide nanoparticles ( $\mathrm{ZnO} \mathrm{NP}$ ) exhibited the best activity compared to all tested metal oxide nanomaterials. ${ }^{11}$ Nanosized particles of $\mathrm{ZnO}$ have been claimed to possess pronounced antimicrobial activities than larger particles; considering the fact that the small size (less than $100 \mathrm{~nm}$ ) and the high surface-to-volume ratio of NP allow for better interaction with bacteria. ${ }^{12}$ Pasquet et $\mathrm{al}^{9}$ revealed that the antimicrobial properties of $\mathrm{ZnO}$ particles are highly affected by its physicochemical properties. This phenomenon may not be prominent in the $\mathrm{NP}$ of $\mathrm{ZnO}$ due to their small diameter which helps in their dispersion in solutions.

Swaroop et $\mathrm{al}^{13}$ reported an increase in the antibacterial properties of $\mathrm{ZnO} \mathrm{NP}$ with $\gamma$ irradiation, on two tested Gram-negative bacteria (Klebsiella pneumoniae and $P$. aeruginosa). However, there are no studies considering the effect of $\gamma$ irradiation on the antimicrobial properties of $\mathrm{ZnO} \mathrm{NP}$ against other organisms. In this regard, ionizing radiation has been reported to modify the specific surface area of some solids. ${ }^{14}$

This study aimed to test the possible use of $\mathrm{ZnO} N P$, either unirradiated or $\gamma$-irradiated, as a safe compatible effective preservative in different cosmetic preparations. The sustainability of this preservative effect upon storage was also tested.

\section{Materials and methods}

\section{Samples}

Six types of cosmetic products, without the addition of any preservatives, were used: sunblock cream, foundation cream, moisturizing cream, body lotion, face cream, and scrub cream. The constituents of the tested products are given in Table S1. They were supplied by Dr Joe Factory and Jolly for cosmetics, Cairo, Egypt. All the samples were stored at $4^{\circ} \mathrm{C}$ until use. Prior to use, the samples were inspected for any physical defects. Propylparabens and phenoxyethanol were supplied by Dr Joe Factory and Jolly for cosmetics, respectively. ZnO NP with diameter of 1-100 nm were purchased from Sigma-Aldrich (code: 544906, St Louis, MO, USA). They have a formula weight of $81.39 \mathrm{~g} \mathrm{~mol}^{-1}$ and a specific surface area of $15-25 \mathrm{~m}^{2} \mathrm{~g}^{-1}$.

\section{Microorganisms}

Standard microorganisms were purchased from VACSERA (Giza, Egypt), and these were P. aeruginosa (ATCC 27856), E. coli (ATCC 25922), S. aureus (ATCC 25923), Candida albicans (ATCC 90028), and Aspergillus niger (ATCC 22343). In addition, $P$. aeruginosa, E. coli, S. aureus, and C. albicans isolates that were previously recovered from contaminated cosmetic preparations were also included in the study.

\section{$\gamma$ Irradiation facility}

All irradiations were performed using the cobalt-60 source (Gamma cell 4000A, India) located at the National Center for Radiation Research and Technology, Cairo, Egypt. A dose rate of $1.77 \mathrm{kGy} \mathrm{h}^{-1}$ was used for the experiment.

\section{Minimum inhibitory concentration and minimum bactericidal/fungicidal concentration of $\mathrm{ZnO}$ NP}

The minimum inhibitory concentration (MIC) of $\mathrm{ZnO}$ NP was determined by broth macrodilution method according to the Clinical and Laboratory Standards Institute recommendations. ${ }^{15} \mathrm{ZnO} \mathrm{NP}$ were used in a concentration

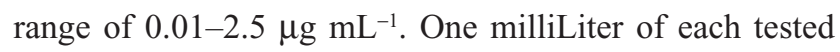
microbial strain, at $5 \times 10^{6} \mathrm{CFUmL}^{-1}$ inoculum density, was added to different $\mathrm{ZnO}$ NP concentrations. They were incubated at $37^{\circ} \mathrm{C}$ for $24 \mathrm{~h}$. The MIC values were taken as the lowest concentration of $\mathrm{ZnO} \mathrm{NP}$ solution that inhibits the microbial growth. The minimum bactericidal/fungicidal concentration (MBC/MFC) was determined by subculturing $50 \mu \mathrm{L}$ from each test tube showing no apparent growth on tryptic soy agar and Sabouraud dextrose agar plates, respectively, and incubating the plates at $37^{\circ} \mathrm{C}$ for $24 \mathrm{~h}$. The least concentration of the test solution showing no visible growth 
(less than $10 \mathrm{CFU} /$ plate) after subculturing was taken as MBC for bacteria and MFC for C. albicans. All measures were taken in duplicate. ${ }^{16}$

\section{Efficiency of $\mathrm{ZnO} N \mathrm{NP}$ as a preservative compared to some commonly used preservatives}

A challenge test was used to investigate the efficiency of $\mathrm{ZnO} \mathrm{NP}$ as a compatible preservative in the tested cosmetic preparations. ${ }^{17}$ Freshly grown culture of the test organisms P. aeruginosa (ATCC 27856), E. coli (ATCC 25922), S. aureus (ATCC 25923), C. albicans (ATCC 90028), and A. niger (ATCC 22343) were harvested in sterile saline and adjusted to a density of $1 \times 10^{8} \mathrm{CFUmL}^{-1}$. They were then used for inoculating $30 \mathrm{~g}$ of each cosmetic preparation, in aseptic state, to reach a final inoculum of $10^{6} \mathrm{CFUg}^{-1}$. Each product was divided into three equal parts and the test preservatives were added in the following concentrations: $\mathrm{ZnO} N \mathrm{NP}$ $\left(0.62 \mu \mathrm{g} \mathrm{g}^{-1}\right)$, propylparabens $(0.3 \%)$, and phenoxyethanol $(2 \%){ }^{18,19}$ All inoculated samples were shaken and incubated at $25^{\circ} \mathrm{C}$ for 28 days. Two grams of the inoculated samples were removed on days $0,7,14$, and 28 and serially diluted in saline to determine their total aerobic microbial count. The efficiency of the dilution as a neutralizer of the preservative activity was confirmed through validation of the recovery of tested organisms.

According to United States Pharmacopeia (USP) 2014, the preservative in a tested sample will pass the test if it causes a reduction in the total aerobic microbial number of the challenging bacteria by $>2 \log$ reduction, from the initial count after 14 days, and no increase from the 14 days count after 28 days of challenge, and no increase from the initial count after 14 and 28 days of challenge with fungi. ${ }^{17}$

\section{Antimicrobial activity of $\gamma$-irradiated $\mathrm{ZnO}$ NP in cosmetic preparations}

The use of $\gamma$ irradiation in microbial decontamination is advantageous for finished cosmetic products as well as raw materials. This method does not leave residues that can be harmful to workers or consumers..$^{20}$ In addition, $\gamma$ irradiation was found to enhance the antimicrobial activity of $\mathrm{ZnO} \mathrm{NP} .{ }^{13}$ Therefore, the antimicrobial activity of in situ $\gamma$-irradiated $\mathrm{ZnO}$ NP was determined through measurement of their inhibition zone diameter against different standard and isolated microbial strains as well as through determination of their effect on the total aerobic microbial count of the different tested preparations.

$\mathrm{ZnO}$ NP were added to each preparation at their MIC $\left(0.62 \mu \mathrm{g} \mathrm{g}^{-1}\right)$. The preparations were then divided into equal parts and exposed to different $\gamma$ radiation doses $(1,3$, $5,7 \mathrm{kGy}$ ). $\gamma$-Irradiated cream portions without $\mathrm{ZnO}$ NP were used as a control.

Determination of inhibition zone diameters against different standard and isolated microbial strains

Overnight cultures of standard and isolated test organisms (S. aureus, P. aureginosa, E. coli, and C. albicans) were

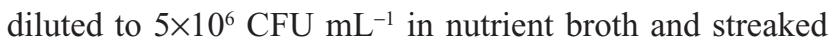
on the surface of solidified tryptic soy agar and Sabouraud dextrose agar plates for bacteria and C. albicans, respectively. Wells were then made in the inoculated agar plates and loaded with $50 \mu \mathrm{g}$ of tested cream portions. The plates were incubated overnight at $37^{\circ} \mathrm{C}$, and the diameters of the inhibition zones were then determined. The inhibition zone diameters were considered as a measure of the antimicrobial activity of irradiated $\mathrm{ZnO}$ NP in different tested preparations against standard and isolated microbial species. ${ }^{21}$

\section{Determination of the total aerobic microbial count in tested preparations}

One gm from each tested preparation was mixed with $9 \mathrm{~mL}$ sterile saline-tween and tenfold serial dilution was made in the same diluents. Aliquots of $0.1 \mathrm{~mL}$ were taken from each dilution and spread, in duplicate, on sterile plates containing tryptic soy agar. They were incubated at $35^{\circ} \mathrm{C} \pm 2{ }^{\circ} \mathrm{C}$ and examined daily for up to $72 \mathrm{~h}$. The mean of the count of duplicate plates was reported in $\mathrm{CFUmL}^{-1}$.

\section{Testing the possible effect of $\gamma$ irradiation on the size of NP}

Dry $\mathrm{ZnO}$ NP powder was suspended in deionized water at a concentration of $0.62 \mu \mathrm{g} \mathrm{mL} \mathrm{m}^{-1}$. This was sonicated at room temperature for $10 \mathrm{~min}$ to form a homogenous suspension. The resulting solution was divided into two portions and irradiated with either 3 or $7 \mathrm{kGy} \gamma$ radiation doses, at room temperature. The average particle size of all samples was studied using Dynamic light scattering (DLS; Malvern, Malvern, UK) and transmission electron microscope (TEM; JEM-2100, Jeol USA, Inc., Peabody, MA, USA). ${ }^{22}$ The particle size of unirradiated solution was used as control.

\section{Antimicrobial activity of unirradiated and $\gamma$-irradiated $\mathrm{ZnO}$ NP during product storage}

The antimicrobial activity of $\mathrm{ZnO} \mathrm{NP}$ during product storage was tested. Each product was divided into three equal parts in separate containers; $\mathrm{ZnO} \mathrm{NP}\left(0.62 \mu \mathrm{g} \mathrm{mL}^{-1}\right)$ were added 
to two of them, and one of the $\mathrm{ZnO}$ NP-containing preparations was exposed to $\gamma$ irradiation dose of $7 \mathrm{kGy}$ (the highest effective dose). The third container was used as a control with no added preservative. The containers were stored for 10 months, and samples were withdrawn every 2 months for the determination of total aerobic microbial count, as described in the "Determination of the total aerobic microbial count in tested preparations" section.

\section{Results and discussion $\mathrm{MIC}$ and MBC/MFC of $\mathrm{ZnO}$ NP}

The MIC and MBC were the same for both the standard and isolated microorganisms: $0.31,0.16,0.62$, and $0.31 \mu \mathrm{g} \mathrm{mL}^{-1}$ for E. coli, S. aureus, P. aeruginosa, and C. albicans, respectively. This indicated that $\mathrm{ZnO} N \mathrm{NP}$ are bactericidal in nature. The differences in the susceptibility of bacteria to ZnO NP was previously reported to be related to the differences in the cell wall structure, cell physiology, metabolism, or the degree of contact. ${ }^{23}$ The high MIC value recorded with $P$. aeruginosa indicated its higher resistance to $\mathrm{ZnO} \mathrm{NP}$, compared to other tested bacteria, which may be due to its intrinsic resistance caused by low intrinsic cell wall permeability and multiple efflux systems. ${ }^{24}$ Higher MIC values of $\mathrm{ZnO} \mathrm{NP}$ against $E$. coli and $S$. aureus $\left(6.25 \mu \mathrm{g} \mathrm{mL}^{-1}\right.$ for both) were reported by Singh et al. ${ }^{12}$ Also, Yousef et al ${ }^{25}$ reported higher MIC values for $\mathrm{ZnO}$ NP against different organisms. This variation in the MIC values in different studies may be attributed to the difference in the method used for the preparation of NP, which can affect their particle size. ${ }^{25,26}$ Several mechanisms were proposed for the antimicrobial activity of $\mathrm{ZnO}$ NP including the generation of reactive oxygen species and the release of toxic zinc ions which can inhibit the active transport and disturb amino acid metabolism. ${ }^{27}$

\section{The efficiency of ZnO NP as a preservative compared to some commonly used preservatives}

The challenge test revealed that $\mathrm{ZnO}$ NP were superior to propylparabens and phenoxyethanol (the most commonly used preservative). $\mathrm{ZnO}$ NP were capable of fulfilling the USP criteria for preservatives used in topical aqueous preparations in all tested cosmetic preparation types, indicating their compatibility with different preparation constituents (Figure 1). On the contrary, propylparaben was effective as a preservative and fulfilled the USP criteria for preservatives in only the sunblock, moisturizing cream, and the body scrub preparations. However, it failed USP criteria as a preservative in the foundation cream, body lotion, and the face cream (Figure 2). This may be caused by its incompatibility with various components of these preparations. Phenoxyethanol failed to fulfill the USP preservative criteria by the challenge test in any of the tested preparations (Figure 3).

Failure of nonsterile products preservative is well documented. Sutton and Jimenez ${ }^{28}$ reported that $15 \%$ of nonsterile product recalls in the years 2004-2011 were due to microbial contamination. Several cosmetic products recalls due to microbiological contamination still occur frequently. ${ }^{29}$ Therefore, this study highlights the efficiency of $\mathrm{ZnO} \mathrm{NP}$ as a superior preservative to propylparaben and phenoxyethanol. Its safety is well documented. The Scientific Committee on Consumer Safety of the European Commission has documented the safety of using $\mathrm{ZnO}$ NP in topical preparations as an ultraviolet filter in concentrations up to $50 \%$ without any toxic in vivo effect, either acute or chronic. They reported that $\mathrm{ZnO}$ NP either coated or uncoated do not penetrate the skin. They have the advantage of being transparent compared to the larger $\mathrm{ZnO}$ particles. ${ }^{30}$ Several studies also documented the lack of acute dermal toxicity, sensitization, and irritation on using ZnO NP. ${ }^{31,32}$ The US Food and Drug Administration does not approve cosmetic preparations prior to market use. It issued a guidance on the safety of nanomaterials in cosmetic products, in June 2014. ${ }^{33}$ Since then, ZnO NP have been incorporated in a lot of sunblock preparations, ${ }^{34}$ and there has been no documented FDA product recall due to its use. ${ }^{35}$

\section{Antimicrobial activity of $\gamma$-irradiated ZnO NP in cosmetic preparations}

The antimicrobial activity of $\gamma$-irradiated $\mathrm{ZnO}$ NP in the tested cosmetic preparations was confirmed by the presence of inhibition zones as well as by the reduction in the total aerobic microbial count in all tested cosmetic preparations compared to the control (Figures 4 and 5). Cosmetics without $\mathrm{ZnO}$ NP did not show any inhibition zone against the tested microorganisms. The presence of $\mathrm{ZnO} N P$ reduced the initial aerobic microbial count in all of the tested preparations by at least one log. The antimicrobial activity of $\mathrm{ZnO} \mathrm{NP}$ has been previously reported by Yousef et al, ${ }^{25}$ Wang et al, ${ }^{26}$ Liu et al, ${ }^{36}$ Rizwan et al, ${ }^{37}$ and Vani et al. ${ }^{38}$ However, in our study, we proved the compatibility of $\mathrm{ZnO}$ NP with the different tested cosmetics and its possible use in the preservation of these preparations. By applying different $\gamma$ radiation doses to the 
A
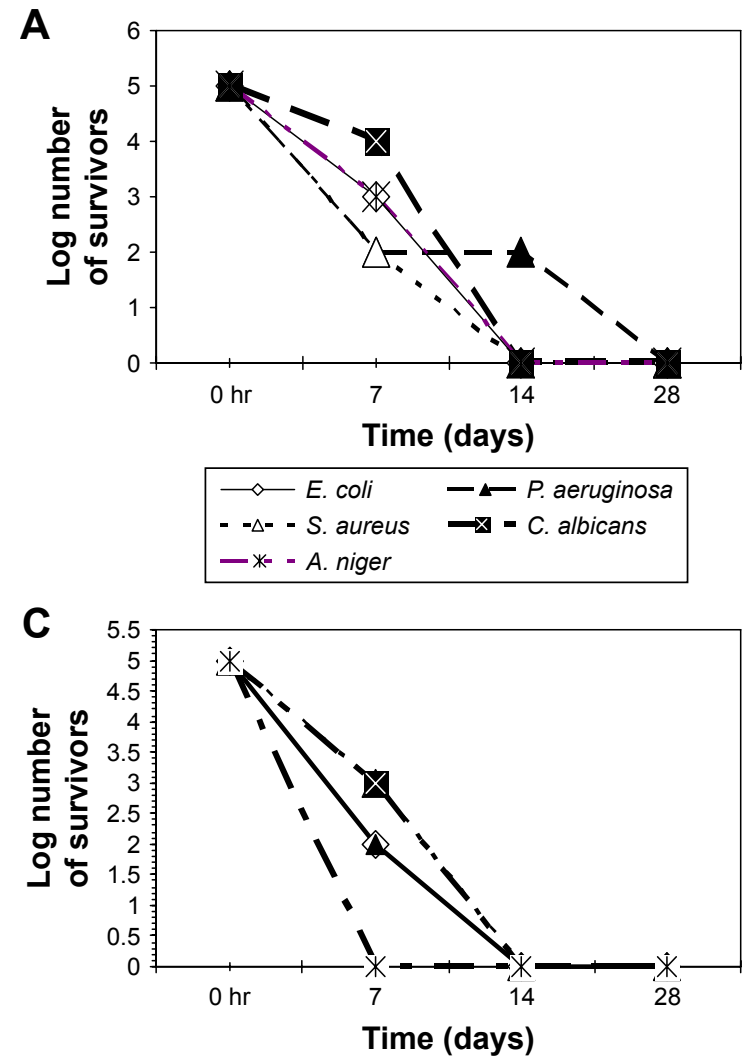

Time (days)
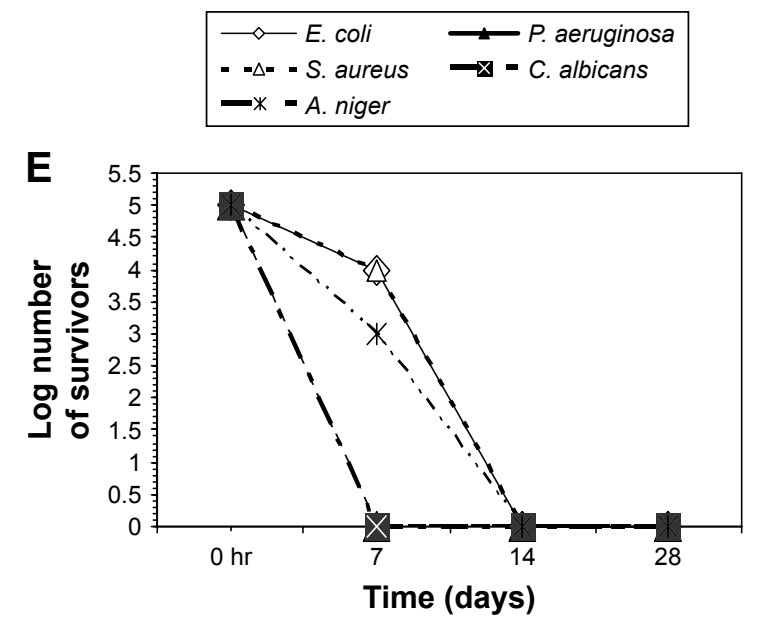

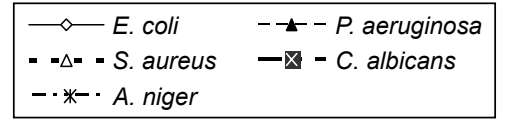
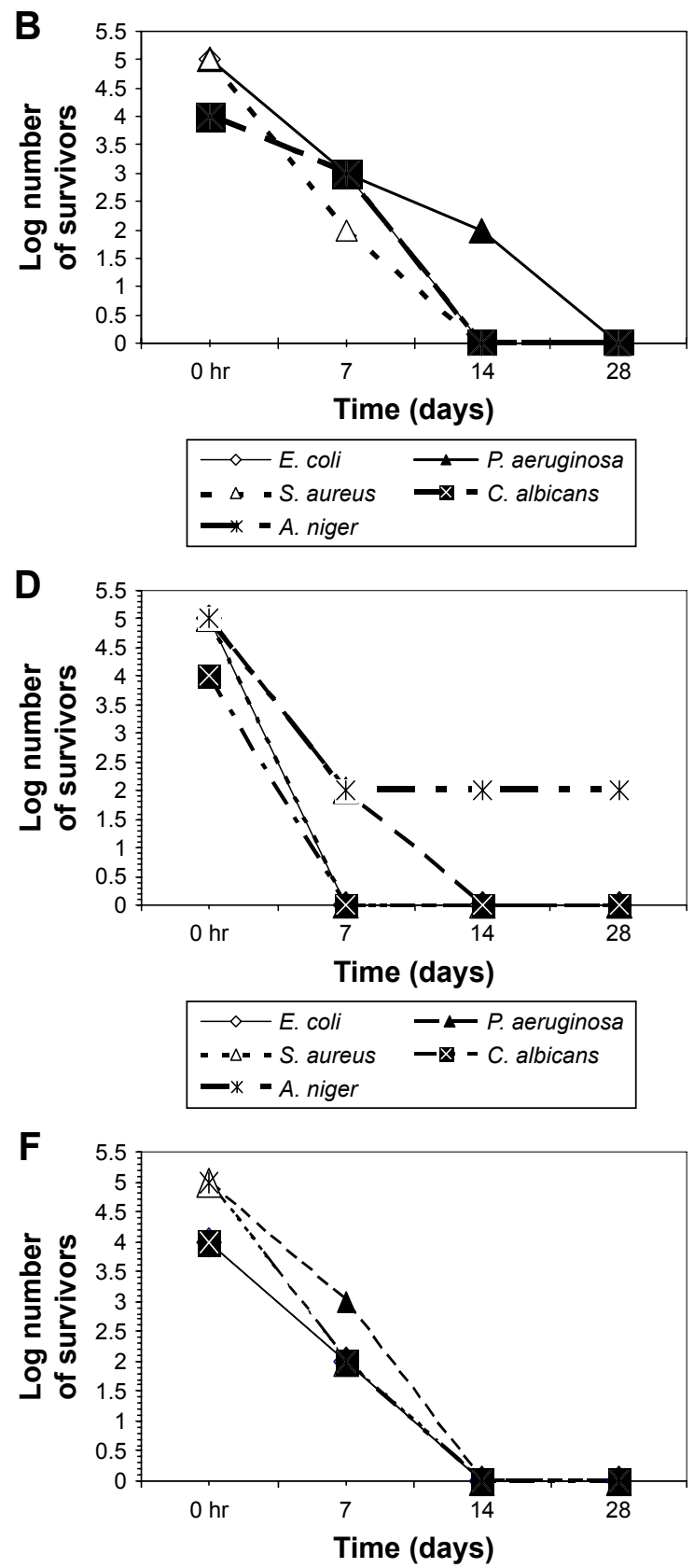

\begin{tabular}{ll}
\hline$\multimap-E . ~ c o l i$ & $- \pm-P$. aeruginosa \\
$\cdots \Delta-$ S. aureus & $\mathbf{x}-$ C. albicans \\
$-*-$ A. niger &
\end{tabular}

Figure I Number of survivors with time in tested preparations challenged with different microorganisms in the presence of ZnO NP as preservative. Note: (A) Sunblock, (B) foundation cream, (C) moisturizing cream, (D) body lotion, (E) face cream, (F) body scrub.

Abbreviations: A. niger, Aspergillus niger; C. albicans, Candida albicans; E. coli, Escherichia coli; P. aeruginosa, Pseudomonas aeruginosa; S. aurerus, Staphylococcus aureus; ZnO NP, zinc oxide nanoparticles.

preparations containing $\mathrm{ZnO} \mathrm{NP}$, the antimicrobial activity of $\mathrm{ZnO} N \mathrm{NP}$ was enhanced with the increase in the radiation dose. This was indicated by the increase in zone diameters against the tested microorganisms (Figure 4) and the decrease in the total aerobic microbial counts (Figure 5) until complete microbial decontamination at 3 or $5 \mathrm{kGy}$ depending on the type of the preparation. The effect of $\gamma$ radiation on the antimicrobial activity of $\mathrm{ZnO} \mathrm{NP}$ has been reported previously on $K$. pneumoniae and $P$. aeruginosa. ${ }^{15}$ In this study, it was clear that applying $\gamma$ radiation on $\mathrm{ZnO} N P$ resulted in enhancing its antimicrobial activity against $S$. aureus, E. coli, C. albicans, and P. aeruginosa. The $\gamma$-irradiated 

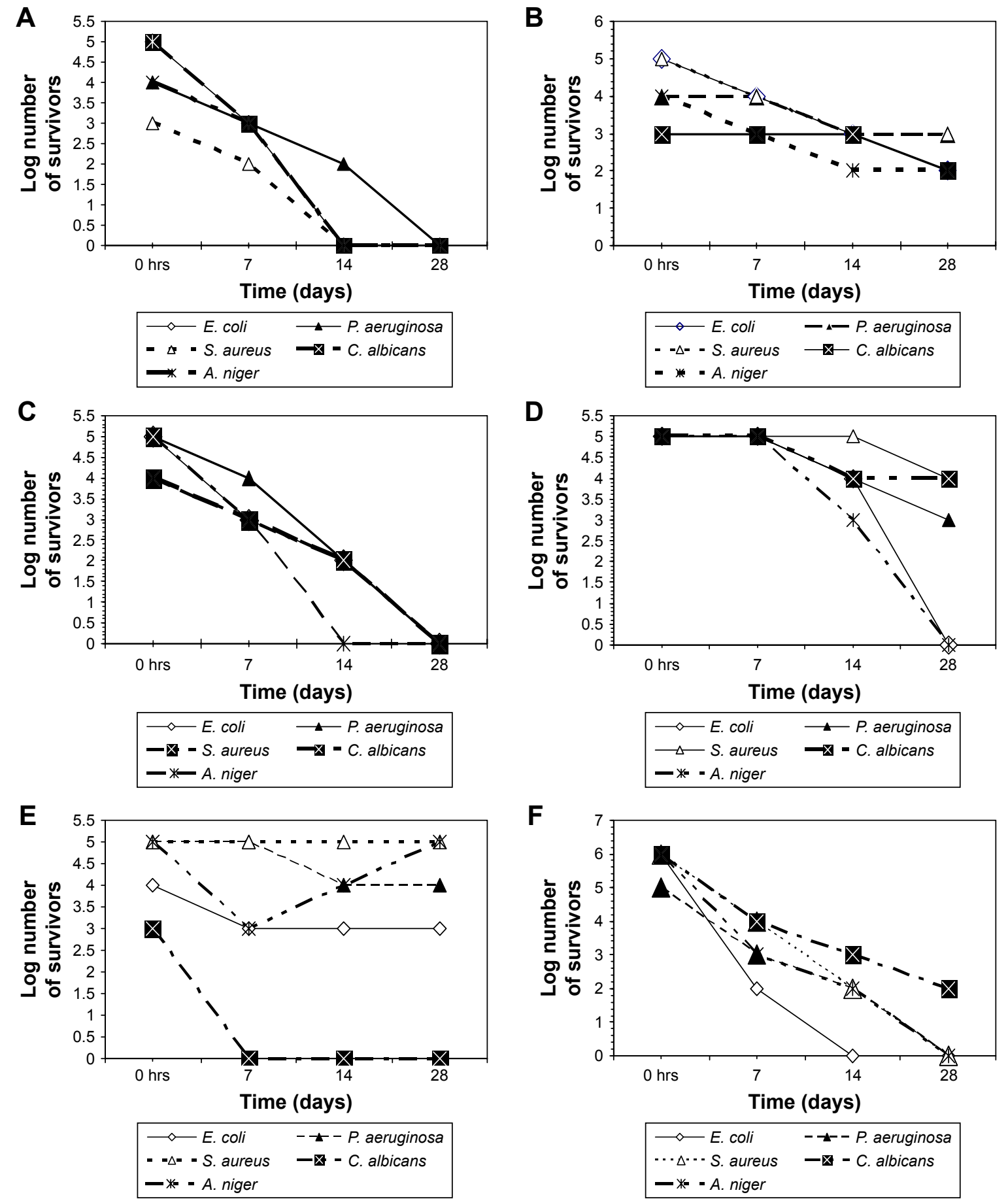

Figure 2 Number of survivors with time in tested preparations challenged with different microorganisms in the presence of propylparaben as preservative. Note: (A) Sunblock, (B) foundation cream, (C) moisturizing cream, (D) body lotion, (E) face cream, (F) body scrub.

Abbreviations: A. niger, Aspergillus niger; C. albicans, Candida albicans; E. coli, Escherichia coli; P. aeruginosa, Pseudomonas aeruginosa; S. aurerus, Staphylococcus aureus; ZnO NP, zinc oxide nanoparticles.

$\mathrm{ZnO}$ NP produced their antimicrobial activity in all tested cosmetic creams, indicating their compatibility with the tested constituents and the possible use of this combination in their preservation. The effect of $\gamma$ irradiation may be due to its activation of $\mathrm{ZnO} \mathrm{NP}$ and the production of
$\mathrm{H}_{2} \mathrm{O}_{2}$ that can penetrate the microbial cell membrane and kill the bacteria. ${ }^{25,39,40}$ Also, it may be due to the reduction in the specific surface area of the particles by irradiation, as reported for some solids. ${ }^{14}$ This possible size reduction was further tested by using TEM and DLS analysis. 
A

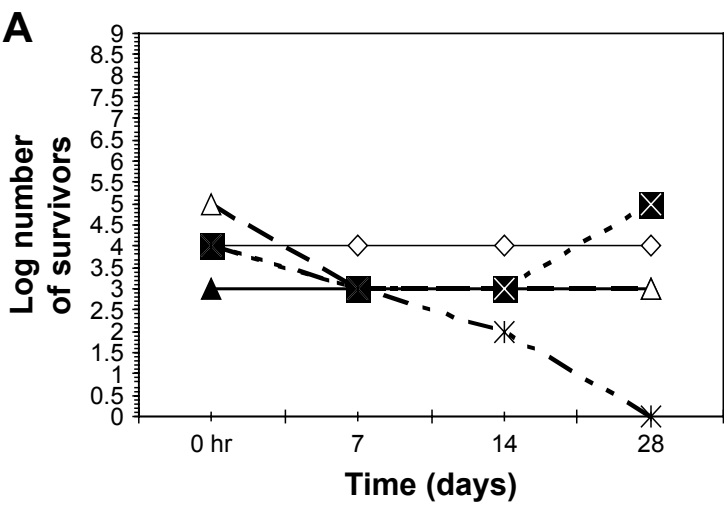

\begin{tabular}{ll|}
$\longrightarrow$ E. coli & $\longrightarrow$ P. aeruginosa \\
$-\Delta-$ S. aureus & $--\square-$ C. albicans \\
$-*-$ A. niger & \\
\hline
\end{tabular}

C

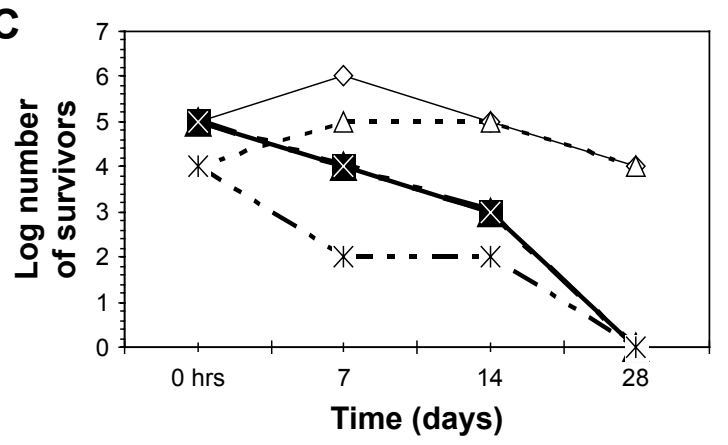

$\mathbf{E}$

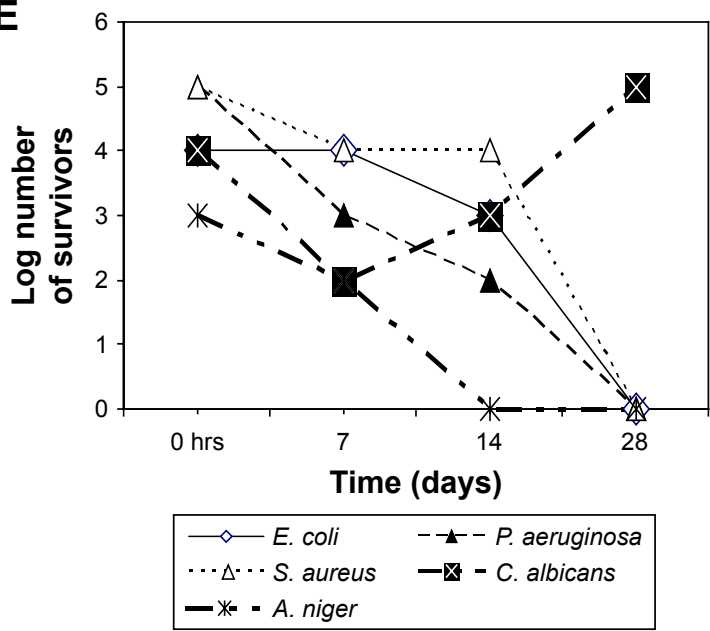

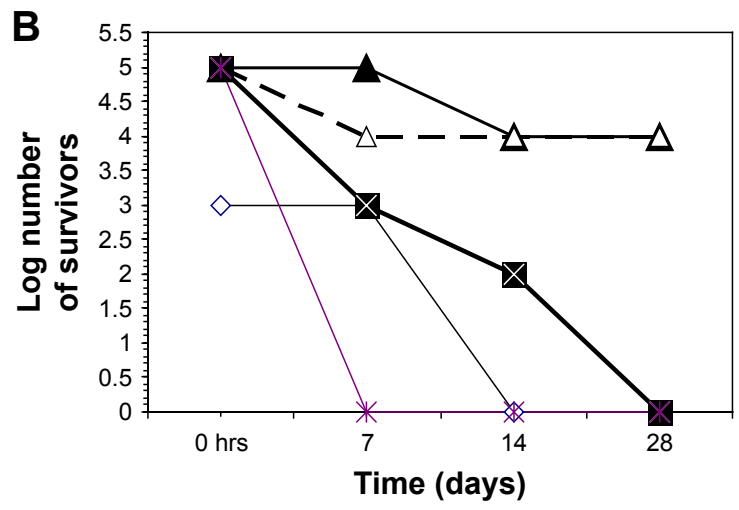

$\longrightarrow$ E. coli
$-\Delta-$ S. aureus
$\longrightarrow$ A. aeruginosa
$\rightarrow$ A. niger

D

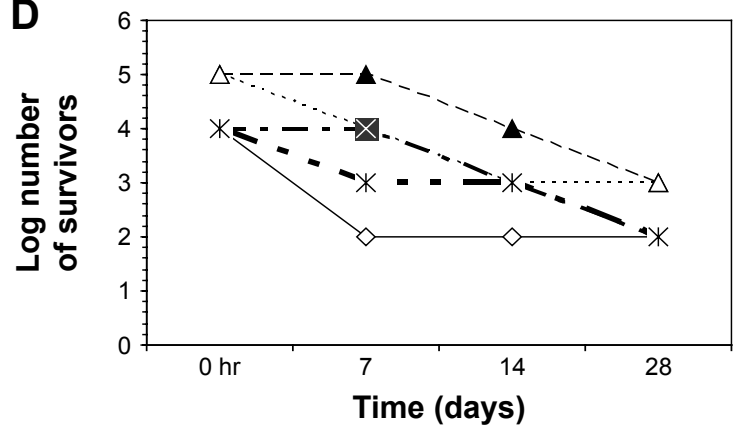

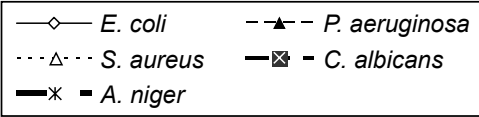

$\mathbf{F}$

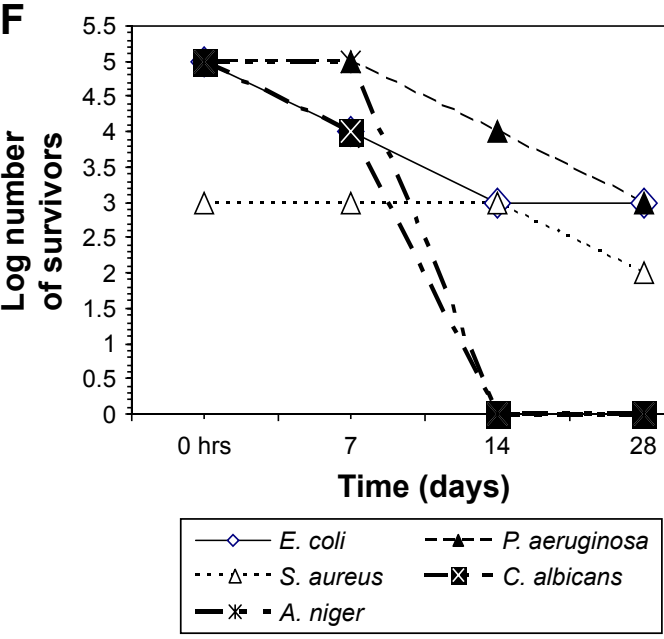

Figure 3 Number of survivors with time in tested preparations challenged with different microorganisms in the presence of phenoxyethanol as preservative. Note: (A) Sunblock, (B) foundation cream, (C) moisturizing cream, (D) body lotion, (E) face cream, (F) body scrub.

Abbreviations: A. niger, Aspergillus niger; C. albicans, Candida albicans; E. coli, Escherichia coli; P. aeruginosa, Pseudomonas aeruginosa; S. aurerus, Staphylococcus aureus; ZnO NP, zinc oxide nanoparticles.

\section{The effect of radiation on the size of $\mathrm{ZnO} \mathrm{NP}$}

The results of the DLS measurement indicated a reduction in the size of $\mathrm{ZnO} \mathrm{NP}$ with $\gamma$ irradiation, with the particle size decreasing with the increase in the radiation dose. The predominant particle sizes were $127.5,110.1$, and $7.5 \mathrm{~nm}$ for unirradiated, 3, and $7 \mathrm{kGy}$-irradiated $\mathrm{ZnO} \mathrm{NP}$, respectively (Table 1). A similar reduction in $\mathrm{ZnO}$ NP size with 
A

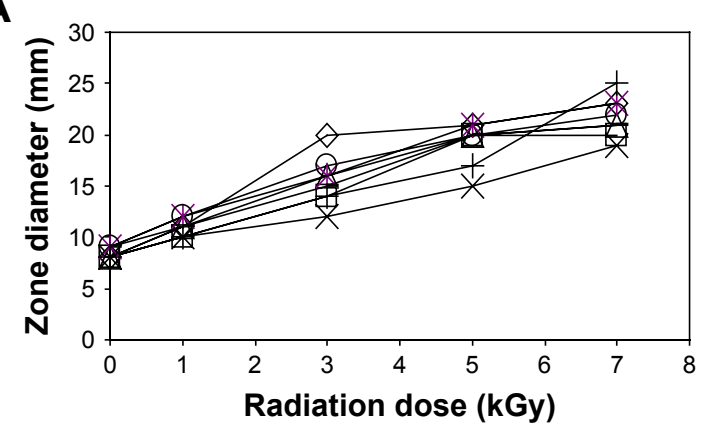

B

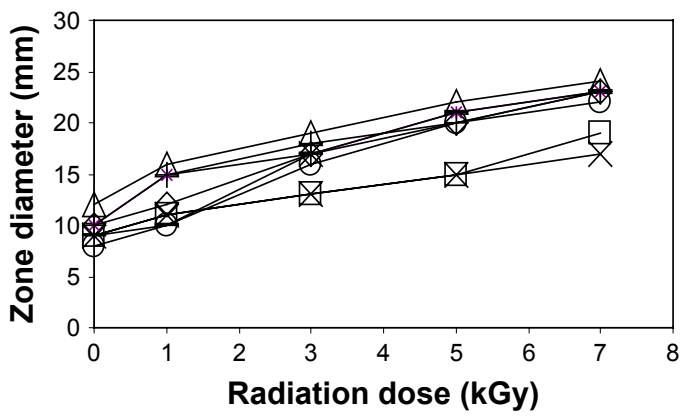

C

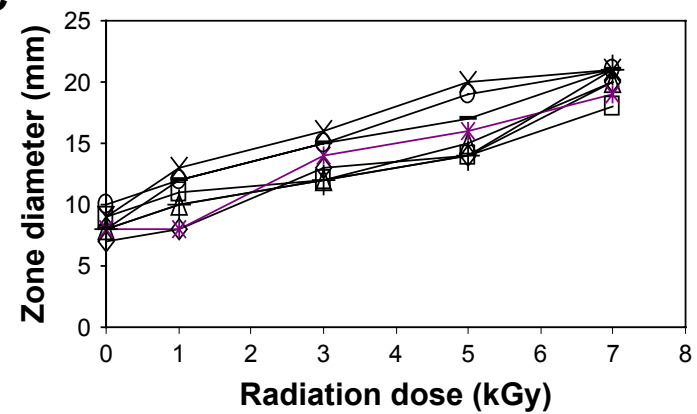

$\smile$ E. coli ATTC $25922 \quad \square-E$. coli isolated

$\triangle$ P. aureginosa ATCC $27853 \rightarrow-P$. aureginosa isolated

* S. aureus ATCC $25923 \rightarrow-S$. aureus isolated

— C. albicans ATCC 90028 C. albicans isolated

E

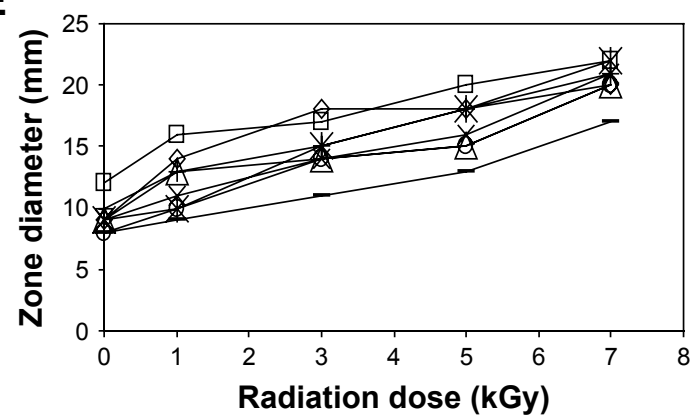

D

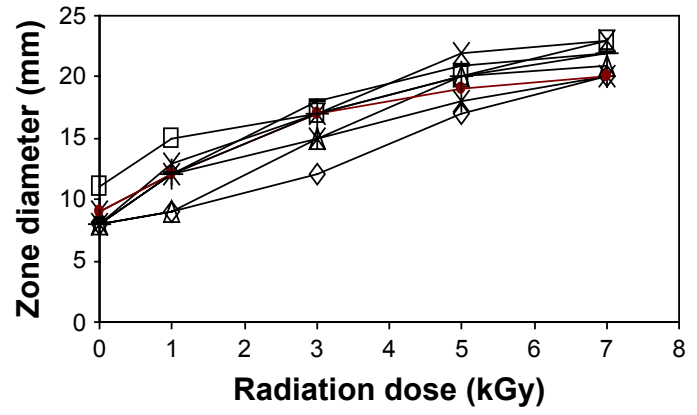

$\mathbf{F}$

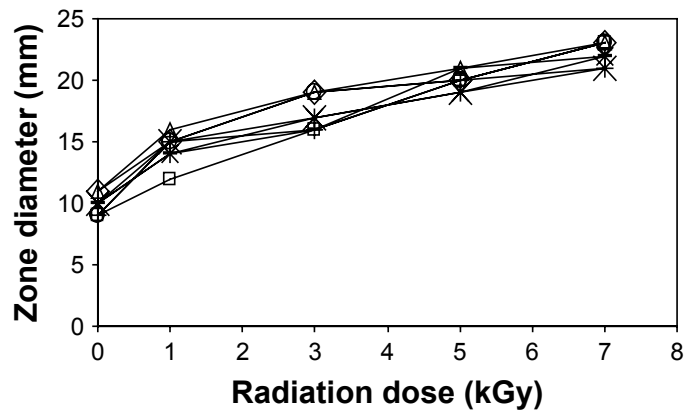

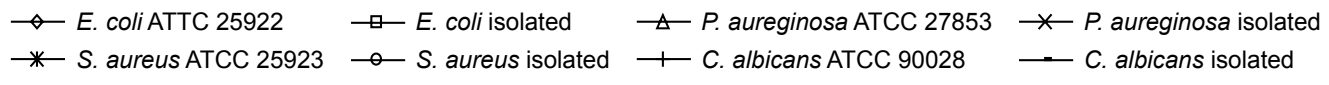

Figure 4 The effect of different $\gamma$ radiation doses on the zone diameters of ZnO NP-containing preparations against different microorganisms.

Note: (A) Sunblock, (B) foundation cream, (C) moisturizing cream, (D) body lotion, (E) face cream, (F) body scrub.

Abbreviations: C. albicans, Candida albicans; E. coli, Escherichia coli; P. aeruginosa, Pseudomonas aeruginosa; S. aurerus, Staphylococcus aureus; ZnO NP, zinc oxide nanoparticles.

$\gamma$ irradiation has been also reported in the TEM micrographs

(Figure 6). To the best of our knowledge, this is the first report on the reduction of $\mathrm{ZnO} \mathrm{NP}$ diameter with $\gamma$ irradiation, and this can account for the enhanced antimicrobial activity of $\mathrm{ZnO} \mathrm{NP}$ with $\gamma$ irradiation.
The antimicrobial activity of unirradiated and $\gamma$-irradiated $\mathrm{ZnO}$ NP during product storage

Preparations containing unirradiated $\mathrm{ZnO} \mathrm{NP}\left(0.6 \mu \mathrm{g} \mathrm{g}^{-1}\right)$ showed no detected growth (count $<10 \mathrm{CFUg}^{-1}$ ) up to 

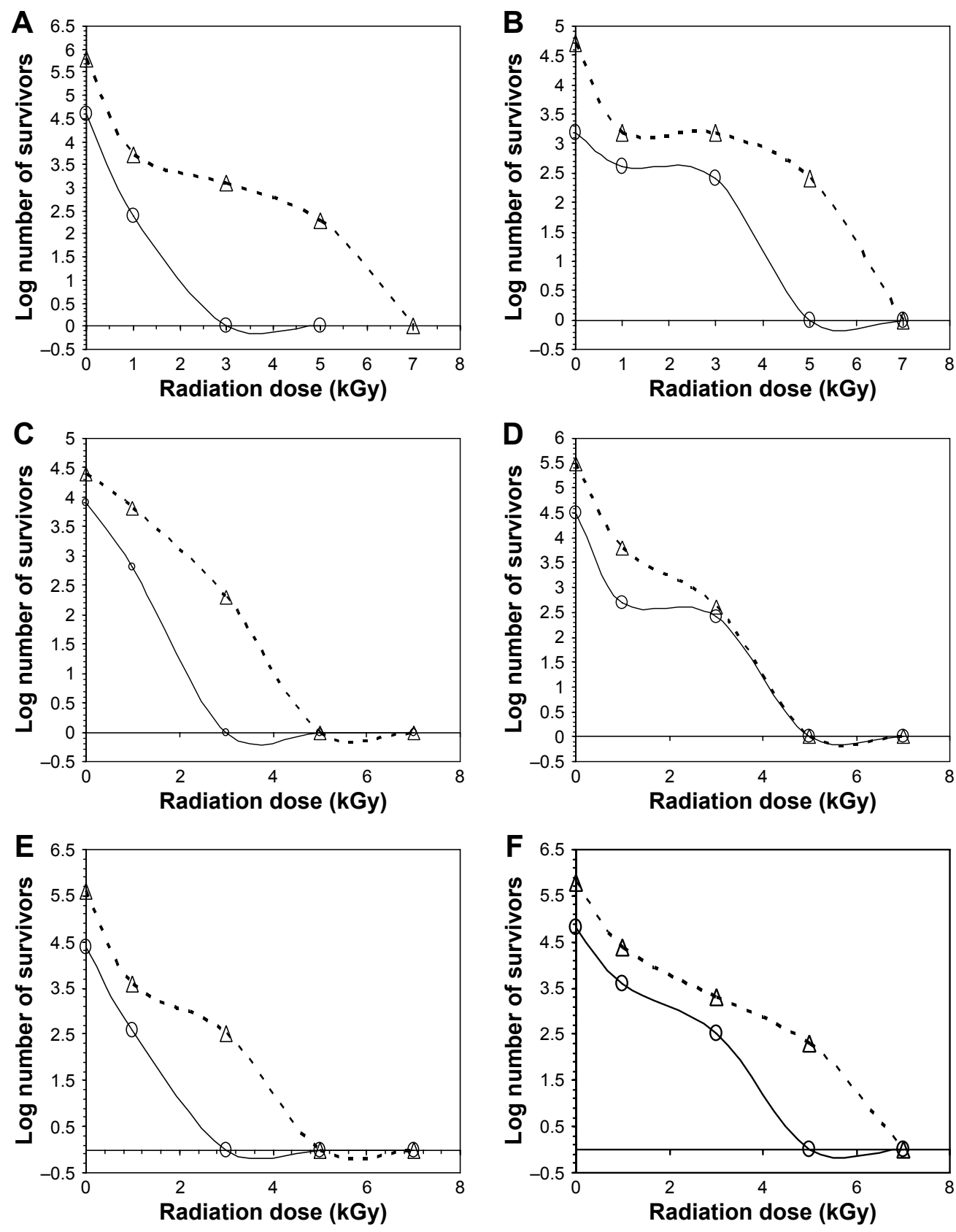

$\because-\Delta-$ Without ZnO NP $\longrightarrow$ With the ZnO NP

Figure 5 The effect of different $\gamma$ radiation doses on the total aerobic microbial count in cosmetic preparations with and without $0.62 \mu g g^{-1} \mathrm{ZnO}_{\mathrm{NP}}$. Note: (A) Sunblock, (B) foundation cream, (C) moisturizing cream, (D) body lotion, (E) face cream, (F) body scrub. Abbreviation: $\mathrm{ZnO} \mathrm{NP}$, zinc oxide nanoparticles.

Table I The average and predominant particle sizes of $\mathrm{ZnO}$ NP subjected to different $\gamma$ radiation doses as determined by DLS

\begin{tabular}{lll}
\hline$\gamma$ irradiation & $\begin{array}{l}\text { Average particle } \\
\text { size }(\mathbf{n m})\end{array}$ & $\begin{array}{l}\text { Predominant } \\
\text { particle size }(\mathbf{n m})\end{array}$ \\
\hline 0 (unirradiated) & $70.9-307$ & 127.5 \\
3 & $61.2-265.6$ & 110.1 \\
7 & $4.8-18.17$ & 7.5 \\
\hline
\end{tabular}

Abbreviations: DLS, dynamic light scattering; ZnO NP, zinc oxide nanoparticles.
6 months. However, the count reached $10^{2} \mathrm{CFUmL}^{-1}$ after 8 months in most preparations, with no increase thereafter. $\gamma$-irradiated $\mathrm{ZnO}$ NP were superior to unirradiated nanoparticles and kept the microbial count below the detectable level (10 $\mathrm{CFUmL}^{-1}$ ) for up to 10 months except in body scrub preparation where the count reached the acceptable limit $\left(10^{2} \mathrm{CFUmL}^{-1}\right)$ after 10 months (Figure 7). This confirmed 

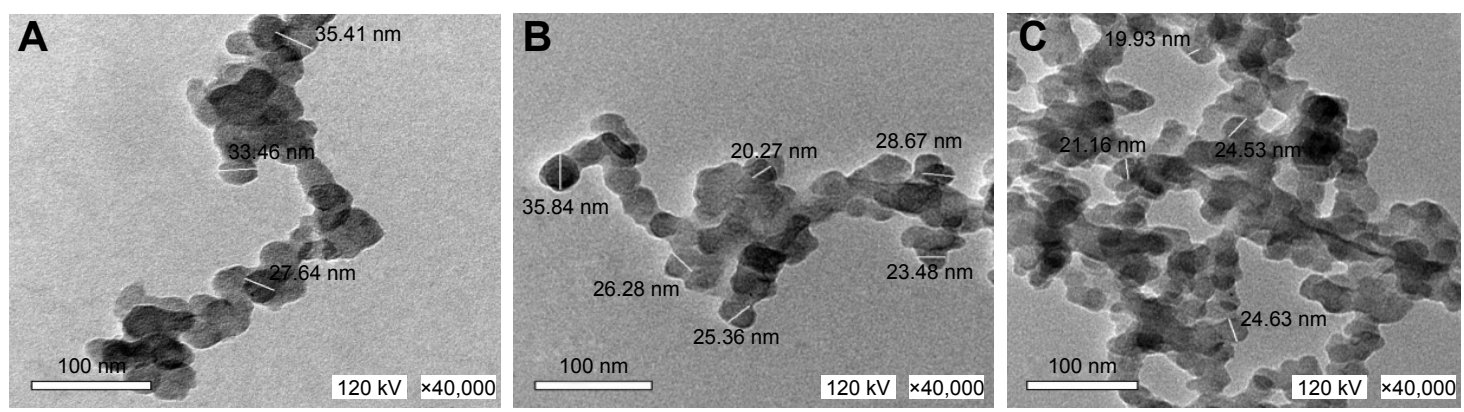

Figure 6 TEM images of $\mathrm{ZnO}$ NP.

Note: (A) Unirradiated, (B) irradiated at $3 \mathrm{kGy}$ dose of $\gamma$ radiation, (C) irradiated at $7 \mathrm{kGy}$ dose of $\gamma$ radiation. Abbreviations: TEM, transmission electron microscopy; ZnO NP, zinc oxide nanoparticles.
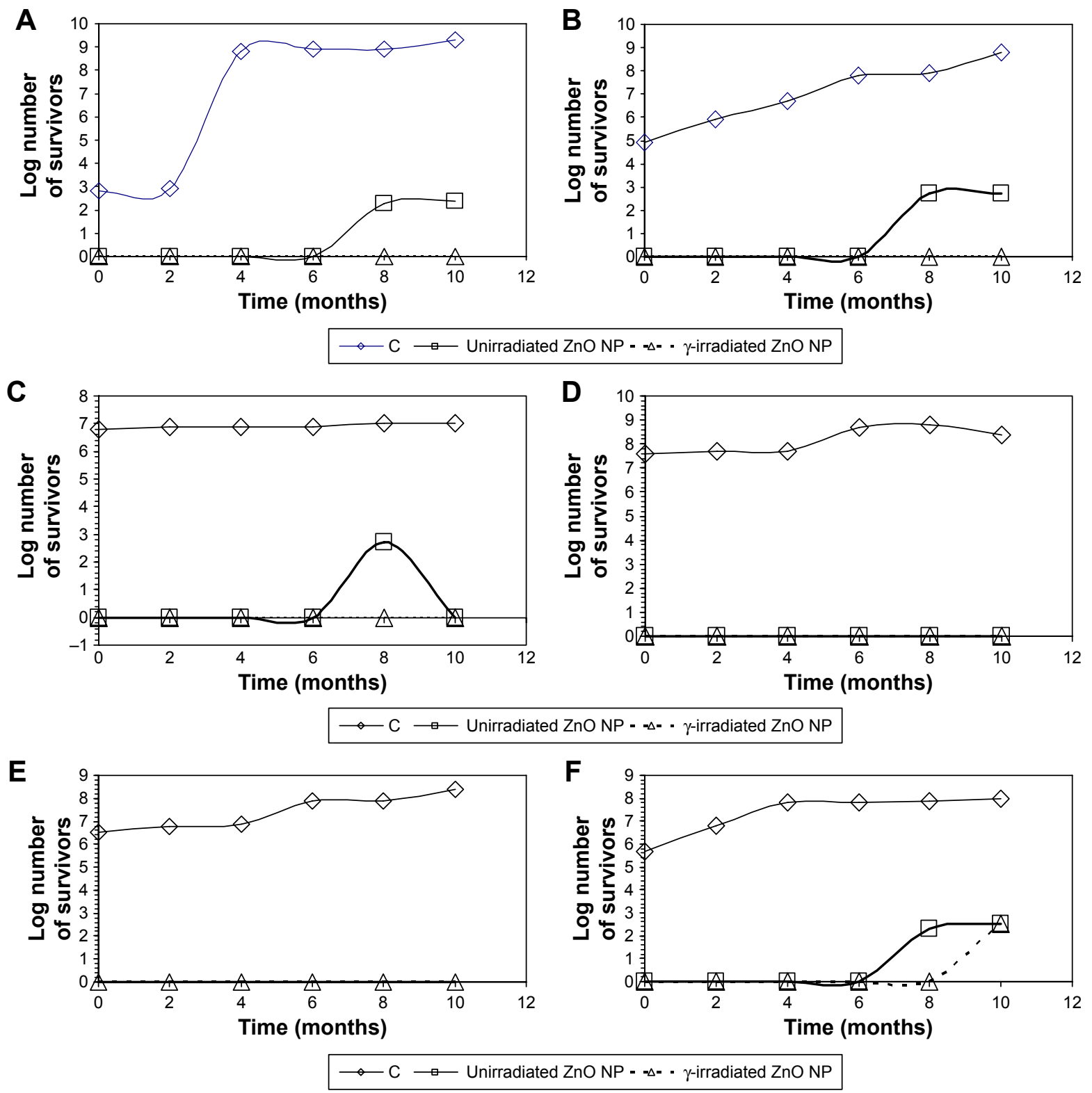

Figure 7 The number of survivors in cosmetic preparations, either without $\mathrm{ZnO} N P(C)$ or containing unirradiated and $\gamma$-irradiated $\mathrm{ZnO} \mathrm{NP}$, with time. Note: (A) Sunblock, (B) foundation cream, (C) moisturizing cream, (D) body lotion, (E) face cream, (F) body scrub. Abbreviation: $\mathrm{ZnO} N \mathrm{~N}$, zinc oxide nanoparticles. 
the efficiency of $\mathrm{ZnO} \mathrm{NP}$ as a preservative in cosmetic preparations and the effect of $\gamma$ radiation on enhancing their activity. In addition, unirradiated and $\gamma$-irradiated $\mathrm{ZnO} \mathrm{NP}$ proved to be compatible with the components of the tested preparations during the product storage. The only limitation of this study is the short storage period, and so longer storage periods need to be tested.

\section{Conclusion}

$\mathrm{ZnO}$ NP have a strong antimicrobial preservative activity against pathogenic organisms in topical preparations. This activity is enhanced by $\gamma$ irradiation, mainly due to particle size reduction. ZnO NP provide a superior, safe, and more effective alternative to commonly known preservatives, and they also proved to be stable on storage.

\section{Disclosure}

The authors report no conflicts of interest in this work.

\section{References}

1. Haftbaradran B, Abedi D, Jalili M, Bagherinejad MR. Microbial quality survey of sunscreen products in Iranian market. Adv Biomed Res. 2014;3:180.

2. Hugbo PG, Onyekwelli OA, Igwe I. Microbial contamination and preservative capacity of some brands of cosmetic creams. Trop J Pharm Res. 2003;2:229-234.

3. Campana R, Scesa C, Patrone V, Vittoria E, Baffone W. Microbiological study of cosmetic products during their use by consumers: health risk and efficacy of preservative systems. Lett Appl Microbiol. 2006;43:301-306.

4. Neza E, Centini M. Microbiologically contaminated and over-preserved cosmetic products acccording rapex 2008-2014. Cosmetics. 2016; 3(3):1-11.

5. Okeke IN, La Mikanara A. Bacteriological of skin moisturizing creams and lotions distributed in tropical developing country. $J$ Appl Microbiol. 2001;91:922-928.

6. Tan ASB, Tuysuz M, Otuk G. Investigation of preservative efficacy and microbiological content of some cosmetics found on the market. Pak J Pharm Sci. 2013;26:153-157.

7. Roden K. Preservatives in personal care products. Official J Austr Socie Micro Inc. 2010;31:195-197.

8. Yazar K, Johnsson S, Lind M, Boman A, Liden C. Preservatives and fragrances in selected consumer-available cosmetics and detergents. Contact Dermatitis. 2010;64:265-272.

9. Pasquet J, Chevalier Y, Couval E, et al. Antimicrobial activity of zinc oxide particles on five micro-organisms of the challenge tests related to their physicochemical properties. Int J Pharm. 2014;460:92-100.

10. Pasquet J, Chevalier Y, Couval E, Bouvier D, Bolzinger M. Zinc oxide as a new antimicrobial preservative of topical products: interactions with common formulation ingredients. Int J Pharm. 2015;479:88-95.

11. Azam A, Ahmed AS, Oves M, Khan MS, Habib SS, Memic A. Antimicrobial activity of metal oxide nanoparticles against Gram-positive and Gram-negative bacteria: a comparative study. Int J Nanomed. 2012; 7:6003-6009.

12. Singh BN, Rawat AKS, Khan W, Naqvi AH, Singh BR. Biosynthesis of stable antioxidant $\mathrm{ZnO}$ nanoparticles by pseudomonas aeruginosa rhamnolipids. PLoS One. 2014;9:e106937.
13. Swaroop K, Sheikh S, Chandrashekar KR, Somashekarappa H. Antibacterial studies of gamma irradiated zinc oxide nanoparticles on Klepsiella pneumonia and Pseudomonas aeruginosa. IOSR J Appl Phys. 2015;7:58-63.

14. El-molla SA, Ismail SA, Ibrahim MM. Effect of gamma irradiation and aging on surface and catalytic activity of nanosized $\mathrm{CuO} / \mathrm{MgO}$ system. J Mex Chem Soc. 2011;55(3):154-163.

15. Clinical and Laboratory Standards Institute (CLSI). Performance Standards for Antimicrobial Disk Susceptibility Tests M02-A11. 11th ed. Wayne, PA: Clinical and Laboratory Standards Institute; 2012.

16. Singh P, Nanda A. Antimicrobial and antifungal potential of zinc oxide nanoparticles in comparison to conventional zinc oxide particles. J Chem Pharm Res. 2013;5(11):457-463.

17. United States Pharmacopeia (USP). Chapter 51, Antimicrobial Effectiveness Testing. Available from: http://www.pharmacopeia.cn/v29240/ usp29nf24s0_c51.html. Accessed January 2, 2017.

18. Cashman AL, Warshaw EM. Parabens: a review of epidemiology, structure, allergenicity, and hormonal properties. Dermatitis. 2005;16(2): $57-66$.

19. Nicole V, Nguyen K, Kupiec TC. The essentials of United States pharmacopeia chapter $\langle 51\rangle$ antimicrobial effectiveness testing. Int J Pharm Compd. 2014;18(2):123-130.

20. Ribeiro MH, Oliveira RS, Desantana MF. In vitro evaluation of gamma irradiation on a gel formation of Cratylia Mollis: rheological properties and microbiological control. J Cosmet Derm Sci Appl. 2012; (2):45-50.

21. Karvani ZE, Cherazi P. Antibacterial activity of $\mathrm{ZnO}$ nanoparticles on gram-positive and gram-negative bacteria. Afr J Microbiol Res. 2011; 5(12):1368-1373.

22. Ghorbani HR, Mehr FP, Pazoki H, Rahmani BM. Sysnthesis of ZnO nanoparticles by precipitation method. Orient J Chem. 2015;31(2): 1219-1221.

23. Slman A. Antibacterial activity of $\mathrm{ZnO}$ nanoparticles on some grampositive and gram negative bacteria. Iraqi J Phys. 2012;18(10):5-10.

24. Bayroodi E, Razieh J. Modulation of antibiotic resistance in pseudomonas aeruginosa by $\mathrm{ZnO}$ nanoparticles. Iran J Microbiol. 2016;8: 85-92.

25. Yousef J, Danial E. In vitro antibacterial activity and minimum inhibitory concentration of zinc oxide and nano-particle zinc oxide against pathogenic strains. J Healt Sci. 2012;2(4):38-42.

26. Wang C, Liu L, Zhang A, Xie P, Lu J, Zou X. Antibacterial effects of zinc oxide nanoparticles on Escerichia coli K 88. Afr J Biotechnol. 2012;11(44):10248-10254.

27. Sirelkhatim A, Mahmud S, Seeni A, et al. Review on zinc oxide nanoparticles: antibacterial activity and toxicity mechanism. Nano-Micro Lett. 2015;7(3):219-242.

28. Sutton S, Jimenez LA. Review of reported recalls involving microbiological control 2004-2011 with emphasis on FDA considerations of "Objectionable Organisms". Am Pharmaceut Rev. 2012;15:42-57.

29. US Food \& Drug Administration. Recalls \& alerts. Available from: https://www.fda.gov/Cosmetics/ComplianceEnforcement/ RecallsAlerts/default.htm. Accessed August 1, 2017.

30. European Commission: Health and consumers. Zinc oxide (nano form) Available from: https://ec.europa.eu/health/scientific_committees/ opinions_layman/zinc-oxide/es/1-2/5.htm. Accessed August 1, 2017.

31. Kim S, Heo Y, Choi S, et al. Safety evaluation of zinc oxide nanoparticles in terms of acute dermal toxicity, dermal irritation and corrosion, and skin sensitization. Mol Cell Toxicol. 2016;12(1):93-99.

32. Nohynek GJ, Dufour EK, Roberts MS. Nanotechnology, cosmetics and the skin: is there a health risk? Skin Pharmacol Physiol. 2008;21: 136-149.

33. U.S. Department of Health and Human Services Food and Drug Administration Center for Food Safety and Applied Nutrition. Guidance for Industry Safety of Nanomaterials in Cosmetic Products. Available from: https://www.fda.gov/downloads/Cosmetics/GuidanceRegulation/ GuidanceDocuments/UCM300932.pdf. Accessed June 29, 2017. 
34. Smijs TG, Pavel S. Titanium dioxide and zinc oxide nanoparticles in sunscreens: focus on their safety and effectiveness. Nanotechnol Sci Appl. 2011;4:95-112.

35. US Food \& Drug Administration. Enforcement Report. Available from: https://www.accessdata.fda.gov/scripts/ires/index.cfm. Accessed August 1, 2017.

36. Liu Y, He L, Mustapha A, Li H, Hu ZQ, Lin M. Antibacterial activities of zinc oxide nanoparticles against Escherichia coli O 157:H7. J Appl Microbiol. 2009;107:1193-1201.

37. Rizwan W, Young-Soon K, Amrita M, Soon-II Y, Hyung-Shik Sh. Formation of $\mathrm{ZnO}$ micro-flowers prepared via solution process and their antibacterial activity. J Nanoscale Res Lett. 2010; 5(10):1675-1681.
38. Vani C, Sergin GK, Annamalia AA. Study on the effect of zinc oxide nanoparticles in Staphylococcus aureus. Int J Pharma Bio Sci. 2011; 4(2):326-335.

39. Fang M, Chen JH, Xu XL, Yang PH, Hildebr HF. Antibacterial activities of inorganic agents on six bacteria associated with oral infections by two susceptibility tests. Int JAntimicrob Agents. 2006;27:513-517.

40. Blake MD, Maness P, Huang Z, Wolfrum EJ, Huang J, Jacoby WA. Application of photo catalytic chemistry of titanium dioxide to disinfection and the killing of cancer cells. Sep Purif Methods. 1999;28(1): $1-50$. 


\section{Supplementary material}

Table SI List of the 77 raw materials used in manufacture of the six tested products

\begin{tabular}{|c|c|c|c|c|c|}
\hline Sunblock & Foundation cream & Moisturizing cream & Body lotion & Face cream & Body scrub \\
\hline Stearic acid ${ }^{a}$ & Stearic acid ${ }^{a}$ & Lanette I6 (cetyl alcohol) ${ }^{\mathrm{a}}$ & Stearic acid ${ }^{b}$ & Stearic acid ${ }^{b}$ & Stearic acid ${ }^{b}$ \\
\hline Sorbitan stearate & Lanet $\circ(\text { cetearyl alc })^{\mathrm{a}}$ & Lanet o (cetearyl alc) $)^{\mathrm{a}}$ & Lanet o (cetearyl alc) ${ }^{\mathrm{b}}$ & Lanet $\circ(\text { cetearyl alc })^{\mathrm{a}}$ & Citric acid \\
\hline Caprylictriglyceride & Paraffin oila & Paraffin oil ${ }^{a}$ & Glyceryl monostearate $^{a}$ & Paraffin oil ${ }^{b}$ & Propanediol \\
\hline Lanette 16 & Vaseline & Glycerin $^{a}$ & Tapioca starch & Glycerin $^{\mathrm{b}}$ & Sodium benzoate \\
\hline 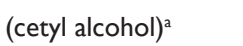 & Isopropyl myristate ${ }^{a}$ & Vaseline & Linalool & Isopropyl myristate ${ }^{b}$ & Lanet o \\
\hline Lanet o & Titanium dioxide ${ }^{\mathrm{a}}$ & Isopropyl myristate ${ }^{\mathrm{a}}$ & Paraffin oil ${ }^{b}$ & Triethanolamine $e^{b}$ & $\left(\right.$ cetearyl alc) ${ }^{\mathrm{a}}$ \\
\hline$\left(\right.$ cetearyl alc) ${ }^{a}$ & Zinc oxide ${ }^{a}$ & Vitamin E & Glycerin $^{\mathrm{b}}$ & Mono propylene glycol ${ }^{b}$ & Carbomer \\
\hline Glyceryl & Octyl methoxy & Triethanolamine $^{\mathrm{a}}$ & Isopropyl myristate ${ }^{b}$ & Tween 80 & Imidazolidinyl urea \\
\hline monostearate ${ }^{\mathrm{b}}$ & cinnamate & Emulgin $B_{2}$ & Triethanolamine $^{\mathrm{b}}$ & Dimethicone silicone & Sodium hydroxide \\
\hline Octocrylene & Jojoba oil & Panthenol & Mono propylene glycol & Fragrance $^{\mathrm{a}}$ & Sodium hydroxide \\
\hline Cetyl palmitate & Emulgin $\mathrm{B}_{2}$ & Mono propylene glycol ${ }^{\mathrm{a}}$ & Dimethicone silicone & & Paraffin oil ${ }^{\mathrm{b}}$ \\
\hline Paraffin oil ${ }^{a}$ & Panthenol & Vitamin A & Butylene glycol & & Glycerin $^{\mathrm{b}}$ \\
\hline Laureth-23 & Silicone oil & Sesame oil & Lanolin alcohol & & Isopropyl myristate ${ }^{\mathrm{b}}$ \\
\hline Glycerin $^{\mathrm{a}}$ & Zinc stearate & Fragrance $^{\mathrm{a}}$ & Sodium carbomer & & Triethanolamine $^{\mathrm{b}}$ \\
\hline Simethicone & Talc powder & Fragrance $^{\mathrm{b}}$ & Limonene & & Titanium dioxide $\mathrm{b}^{\mathrm{b}}$ \\
\hline Vaseline & Mono propylene glycol ${ }^{\mathrm{a}}$ & Butylene glycol & Benzyl silicate & & Zinc oxide ${ }^{\mathrm{b}}$ \\
\hline Allantoin & & Lanolin alcohol & Myristyl alcohol & & Mono propylene \\
\hline Lactic acid & & Sodium carbomer & Petroleum & & glycolb $^{b}$ \\
\hline Isopropyl myristate ${ }^{a}$ & & & Hexyl cinnamal & & Tween 80 \\
\hline Tween 20 & & & & & Dimethicone silicone \\
\hline Vitamin E & & & & & Fragrance $^{\mathrm{a}}$ \\
\hline Glycolic acid & & & & & Scrub (sand) \\
\hline Triethanolamine $\mathrm{e}^{\mathrm{a}}$ & & & & & Calcium \\
\hline Tocopherylacetate & & & & & pantothenate \\
\hline Titanium dioxide $^{a}$ & & & & & Citrus grandis \\
\hline Zinc oxide ${ }^{a}$ & & & & & Pyridoxine $\mathrm{Hcl}$ \\
\hline Benzophenone-3 & & & & & Tocopheryl acetate \\
\hline \multicolumn{6}{|l|}{ Siloxane } \\
\hline \multicolumn{6}{|l|}{ Xanthan Gum } \\
\hline \multicolumn{6}{|l|}{ Avobenzone } \\
\hline \multicolumn{6}{|l|}{ Sucrose cocoate } \\
\hline \multicolumn{6}{|l|}{ Octyl methoxy } \\
\hline \multicolumn{6}{|l|}{ cinnamate } \\
\hline \multicolumn{6}{|l|}{ Jojoba oil } \\
\hline \multicolumn{6}{|l|}{ Iron oxide } \\
\hline Alumina & & & & & \\
\hline
\end{tabular}

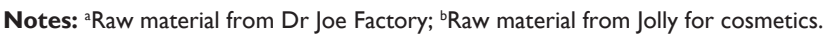

International Journal of Nanomedicine

\section{Publish your work in this journal}

The International Journal of Nanomedicine is an international, peerreviewed journal focusing on the application of nanotechnology in diagnostics, therapeutics, and drug delivery systems throughout the biomedical field. This journal is indexed on PubMed Central, MedLine, CAS, SciSearch $\AA$, Current Contents ${ }^{\circledR} /$ Clinical Medicine,

\section{Dovepress}

Journal Citation Reports/Science Edition, EMBase, Scopus and the Elsevier Bibliographic databases. The manuscript management system is completely online and includes a very quick and fair peer-review system, which is all easy to use. Visit http://www.dovepress.com/ testimonials.php to read real quotes from published authors. 